\title{
An alternative model of reflective teacher supervision
}

\author{
Süleyman Davut Göker ${ }^{1}$
}

\begin{abstract}
Focusing on the promotion of reflectivity during practice teaching amongst teachers, this study aims to explore the impact of a reflective teacher supervision model (RTSM) developed by Goker (2006a) on the development of instructional skills of teachers. Two groups of elementary and secondary school teachers from different fields (24 in total) registered for an MA course, American University, Cyprus were compared to their development of instructional skills. The research approach used for this study was both quantitive and qualitative, which included: (a) conducting a sample lesson based on the pinciples of reflective teaching, (b) expessing results both with statistical data obtained from the pre test and post test results of the Clarity Observation Instrument (Metcalf, 1989) and using interviews and surveys, and anecdotal data. Findings have significant implications for how reflective supervision can be a means to develop instructional skills. Recommendations for teacher education programs and the student teachers are also made.
\end{abstract}

Keywords: Supervision; reflective supervision; teacher supervision; professional leadership

\section{- Introduction}

With its three three major elements, reflective phenomena fosters teachers' reflective thinking: narrative, cognitive, and critical. The cognitive element fosters concern regarding broad teaching principles as well as strategies of classroom management and organization that appear to transcend subject matter (Shulman, 1987, p. 9). This element corresponds with the reflective practice in most personal form - the "inner dialog" a teacher has with herself or himself. The narrative side of reflection both creates a cassroom experience context for teachers and other learners and enables them a deeper analysis of what is actually happening in class and in the teachers' construction of reality. Thus, it is an efficient way of encouraging culturally and developmentally suitable reflective practice (Goker, 2006a).

Reflecting on one's learning enables him or her to link their professional development to practical outcomes and widens the definition of what counts as useful activity (Acheson \& Gall, 2003; Costa \& Garmston, 2002; Bullock \& Hawk 2005). It also makes learners accept responsibility for their personal growth, see a clear link between the effort they put into their development activity and the benefits they get out of it. From a broader perspective, it helps them to see more value in each learning experience, by knowing why they're doing it and what's in it for them and finally enables them to learn how to 'learn' and add new skills over time.

Like other learners, teachers develop and change from the inside out-through personal reflection and practice - and from the outside in — through contact with the experiences and theories of

\footnotetext{
${ }^{1}$ Assist. Prof. Dr., Artvin Çoruh University, Education Faculty, sdgoker@artvin.edu.tr
} 
Göker, S. D. (2016). An alternative model of reflective teacher supervision. Journal of Human Sciences, 13(2), 35603570. doi:10.14687/jhs.v13i2.3868

others in a reflective learning community. The most essential variable in this process is growth, which may be reached through open learning environments and reflective process (Goker, 2006a).

\subsection{Reflective Supervision and Teacher Commitment}

Reflection gives teachers an opportunity to self-evaluate their teaching and practices (Tucker, Stronge, \& Gareis, 2002). Teachers grow professionally if they think about their teaching and what improvements need to be made. This type of supervision is a part of reflective management, which sees schools as communities rather than organizations. The essential goal of reflective teacher supervision is to open the doors for teacher inquiry, a teacher-administrator-driven form of professional growth. With its reconfigured supervision roles and relationship, it mainly reconceptualizes the meaning of supervision, in which schools can try to challenge an embedded traditional 'top-down,' hierarchical paradigm, with the teachers at the bottom as passive recipients of training.

This new definition of supervision is also consistent with recent perspectives on site-based management, the importance of building collaborative cultures and organizational learning communities in schools, and the systemic nature and meaning of school-wide organizational change and improvement. Collectively, these perspectives suggest a much richer cultural view of supervision that reflects the kinds of professional learning environments and organizational climates that teachers and administrators create and sustain in schools where teachers will monitor and adjust learning environments. Quality teaching and learning cannot simply be assumed, but instead result from active ongoing efforts of teachers, principals, and students and a shared commitment to 12 school-based reflective management (SBRM) principles developed by Goker (2006a), which are a reflective learning community, reflective teaching, professional leadership, shared vision and goals, teacher quality, openness about performance data within the school, high expectations, positive reinforcement, monitoring progress, student rights and responsibilities, home-school partnership, context and resources.

\section{- Method}

\section{- Participants and Setting}

This study aims to explore the impact of a reflective teacher supervision model developed by Goker (2006a) on the development of instructional skills of teachers from different disciplines.. Two groups of elementary teachers (24 in total) registered for an MA course named ELTM521 Reflective Teaching offered at the American University, Kyrenia, North Cyprus were compared to their development of instructional skills. The research approach used for this study was both quantitive and qualitative, which included: (a) conducting a sample lesson based on the pinciples of reflective teaching, (b) expessing results both with statistical data obtained from the pre test and post test results of the Clarity Observation Instrument (Metcalf, 1989) and using openended questioning techniques (interviews and surveys), and anecdotal data.

\subsubsection{Reflective Teacher Supervision Model (RTSM) Description.}

In the RTSM model developed by Goker (2006a) on the development of instructional skills of teachers, 12 participants have been chosen among teachers from different disciplines from the elementary and secondary schools. They were expected to have at least 4-year teaching experience, or a master's degree, a minimum of four semesters as a successful 
teacher, and a proof of evidence of having participated in professional activities such as presentations at conferences or activities. Having been chosen, the participants in this group formed 2 teams each consisting of 6 teachers to work collaborately in the supervision of a group of teachers assigned to the entire team. All participants were expected to work with all teachers assigned to the team by means of observations, reflective discussion of student teacher planning and classroom instruction. Thus, each teacher received a minimum of 4 observation sessions for a total of 8 observation sessions for a whole placement (10-week experience) of the teaching practice. In the RTSM model, the role of the RTSM CMT liaison has been re-envisioned from the role of the university supervisor in the traditional triad model. Instead of observing the teachers, the RTSM liaison works together with the RTSM team to make suggestions developed throughout observation sessions.

\subsubsection{Traditional Triad Description}

For the traditional triad at the university, a cooperating teacher is expected to possess the minimum qualifications given: (a) a two-year teaching experience, and (b) have a B a c h el or's degree. The University supervisor (course lecturer) must (a) have a Master's degree, (b) be competent in the content area they will supervise, and (c) have five-year teaching experience. The cooperating teacher and the university supervisor are both responsible for each finishing at least 4 observation sessions for a total of 8 observation sessions for a whole placement (10-week experience) of the teaching practice. 12 teachers receiving split placements (5-week placements for each half of the teaching experience) get 3 three observation sessions each by the cooperating teacher and course lecturer for a total of 8 observation sessions.

\subsubsection{Procedure}

The study was conducted over the course of 6 months between November 5, 2012 and May 17, 2013. The researcher used open-ended surveys, interviews, and anecdotal data (e.g., field notes from observation forms, orientation meetings and informal discussions) along with the Clarity Observation Instrument (Metcalf, 1989) as the main instrument. The Clarity Observation Instrument (Metcalf, 1989) was administered to see treatment effects on impovement of any of the seven instructional skills, which may result in measures of frequency of quality, occurrence, and overall demonstration (i.e., the degree to which there was evidence of all instructional skills in a lesson).

\subsubsection{Data Collection and Analysis}

Trainees were naturally expected to realize their weaknesses and strengths during preparation for their reflective teaching practice, final written report, self-evaluation of teaching experience, and fnal evaluation by cooperating teachers and course lecturer. There were 6 male and 6 female student teachers both in the experimental group (n12) and control group (n12). They ranged in age from 24 to 35 years. Each participant had taken part in one previous School Experience course during their freshman and junior year and had taken other prior education courses

A 20-h orientation on reflective teaching was held prior to the 7-week investigation. Teachers were told whether they were part of the experimental or control group. The orientation employed an overview of the seven clarity skills representing desired teacher behaviors. 
Further, the participants were introduced to the type of sample lesson with all lesson plans including the procedures to be implemented in the pre-, during-, and post-sessions they would be required to teach weekly during their reflective teaching course. The researcher modeled a typical lesson based on the pinciples of reflective teaching and a simulated post-conference following the lesson was conducted by the researcher and a teacher volunteer. To be able to provide a structure for organizing subsequent post-conferences, these questions were asked: (a) What were the strengths and weaknesses? (b) If you were to teach this lesson again, how would you do it? The researcher also examined the participants' perceptions of: (a) the quality of supervision provided by the RSTM team and the traditional triad as partial requirements of RTSM 'reflective teacher supervision model', (b) their relationships with the RTSM participants and the traditional triad members, and (c) any problems or concerns that arose during the reflective teaching practices. Focus group interviews were used to provide information about the perceptions of the participants and encourage discussion durng the simulated post-conference following the lessons. The research approach used for this study was both quantitive and qualitative, which included: (a) conducting a sample lesson based on the pinciples of reflective teaching, (b) expessing results both with statistical data obtained from the pre test and post test results of the Clarity Observation Instrument (Metcalf, 1989) and c) conducting interviews with the teachers, RSTM team, and d) collecting anecdotal data (e.g., fieldnotes, journals) from selected participants.

Interviews were organized to clarify the preliminary results of the teacher surveys and they focused on: (a) roles of the participants, (b) their relationships with the other participants (c) advantages and disadvantages of the R S T model, and (d) the participants' opinions of the supervision in the RST model.

Data obtained from all these sources were analyzed for emerging patterns and trends making us e of constant comparative analysis (Miles \& Huberman, 1984), in which the members of the research team read all the data carefully and developed a matrix using the recurring themes. To be able to code the frequency of the references for the models and the participants in the models, a table was developed and representative quotations of the themes were selected. Data collected were triangulated across the research team (two lecturers and one doctoral student in teacher education) and data sources (e.g., interviews, surveys, field notes) to be able to produce an accurate presentation of the findings, as well as to control for researcher bias.

The researcher video-taped lessons in the classrooms for all participants during Week 1 and audiotaped post-conferences to collect data. Participants attended weekly 90-min seminars; experimental and control group teachers attended separately in weeks 2-6. 50 videotapes (25 from preassessment and 25 from post-assessment) were organized and scored originating from the data sources independently following training; each rater assessed every tape and during the ratings, one videotape was randomly selected to determine if interrater reliability was being maintained. This type of selection resulted in inter-rater agreement of $83 \%$ for frequency of occurrence, $86 \%$ for quality of use, and $91 \%$ for overall demonstration.

\subsubsection{Research Questions}

In this study, it was hypothesized that teachers would increase demonstrations and effectiveness of instructional skills through the RTSM 'reflective teacher supervision model', developed by the researcher when compared to traditional triad model. So, the following research questions are posed, as the study inquires into the relationship of reflective supervision to the pedagogical performance of teachers: 
Göker, S. D. (2016). An alternative model of reflective teacher supervision. Journal of Human Sciences, 13(2), 35603570. doi:10.14687/jhs.v13i2.3868

1. To what extent can reflective teacher supervision model increase instructional skills of teachers?

2. Which supervision model (RTSM or traditional triad model) is more effective in increasing demonstrations and instructional skills?

3. What are the levels of satisfaction with the reflective supervison model utilized mong teachers in each group as compared to those of a traditional triad model?

\subsubsection{Limitations of the Study}

In this study, intensive efforts were made to control researcher bias. However, a limitation of the study may be that the researcher serves as both a course lecturer and supervisor and a RTSM team and may have brought his own perceptions of the models to the analysis. The use of focus group interviews may also have been another limitation to a certain degree since some participants may have been influenced by the opinions and comments of other members of the focus group (Krueger, 1994).

\section{- Findings and Discussion}

The discussion of the results is organized around both research questions and 12 (SBRM) principles developed by Goker (2006a), which are a reflective learning community, reflective teaching, professional leadership, shared vision and goals, teacher quality, openness about performance data within the school, high expectations, positive reinforcement, monitoring progress, student rights and responsibilities, home-school partnership, context and resources that reflect the purpose and research questions of the study.

\section{- Research question one}

As can be seen from Tables 1 and 2, group means were not equal at pre- assessment for instructional (clarity) skills variables. An analysis of co-variance was used to test for statistical significance. Between-group mean score comparisons at post-assessment indicated statistical significance in favor of the experimental group, F (1,27) D 244.40, $\mathrm{p}<.001$.

Although participants' responses during post-conferences mainly focused on clarity skills, there was also much discussion on materials, the task, and students. The following examples show how participants were sensitive in creating a reflective learning community through a collaborative effort or teamwork exhibited by each team which included R TS member and t eachers. With the RTS model, the possibility of opportunity for a group of teachers to be involved in a reflective learning community was regarded as a real benefit. One RTS member interviewed explained: "I seldom spoke to the supervisor but here I had more support for myself." Another member interviewed said: "I do not remember any time I had an opportunity to discus s with a supervisor but here all people are acting as reflective learners and there is much more than a supervisor can do." 
Göker, S. D. (2016). An alternative model of reflective teacher supervision. Journal of Human Sciences, 13(2), 35603570. doi:10.14687/jhs.v13i2.3868

Table 1 Means and standard deviations for instructional skills

\begin{tabular}{|c|c|c|c|c|}
\hline \multirow{2}{*}{ Clarity (instructional) skills } & \multicolumn{2}{|c|}{$\begin{array}{c}\text { Control } \\
\text { group }\end{array}$} & \multicolumn{2}{c|}{$\begin{array}{c}\text { Experimental } \\
\text { group }\end{array}$} \\
\cline { 2 - 5 } & Pre & Post & Pre & Post \\
\hline (1) Stating objectives & & & & \\
\hline M & 3.36 & 4.87 & 4.45 & 9.86 \\
\hline SD & 1.63 & 3.85 & 1.76 & 2.09 \\
\hline (2) Repeating points & & & & \\
\hline M & 4.57 & 6.65 & 4.90 & 10.87 \\
\hline SD & 1.58 & 4.23 & 2.45 & 2.60 \\
\hline (3) Using examples & & & & \\
\hline M & 4.44 & 7.48 & 5.38 & 11.67 \\
\hline SD & 1.66 & 2.97 & 2.21 & 2.11 \\
\hline (4) Repeating items & & & & \\
\hline M & 3.36 & 4.23 & 4.13 & 10.73 \\
\hline SD & 1.45 & 1.73 & 1.70 & 2.41 \\
\hline (5) Asking questions & & & & \\
\hline M & 5.79 & 7.90 & 6.15 & 11.96 \\
\hline SD & 2.56 & 2.36 & 1.81 & 1.74 \\
\hline (6) Student questions & & & & \\
\hline M & 4.77 & 4.75 & 5.90 & 10.86 \\
\hline SD & 1.90 & 2.51 & 2.14 & 3.21 \\
\hline (7) Practice time & & & & \\
\hline M & 4.97 & 10.22 & 5.46 & 11.96 \\
\hline Overall mean score & 2.26 & 2.89 & 1.27 & 2.43 \\
\hline & 4.86 & 7.45 & 6.21 & 11.58 \\
\hline
\end{tabular}

In relation to the notion of team work for the teachers, one of the RTS member explained that the RTS model brings teachers to ge ther because "it's just us and it's really all of us."

Regarding shared vision and goals, a teacher explained: "They really helped to see me any time I wanted ". One teacher interviewed explained this: "I thought that their contribution to my teaching style and methodology was great as they came from different departments." Similarly, a secondary school teacher made comments on the different dimensions given by the team of elementary RTSM team. "That was great to see different teachers from subject areas to observe me." 
Göker, S. D. (2016). An alternative model of reflective teacher supervision. Journal of Human Sciences, 13(2), 35603570. doi:10.14687/jhs.v13i2.3868

Table 2 Means and standard deviations for quality of use

\begin{tabular}{|c|c|c|c|c|}
\hline $\begin{array}{c}\text { Clarity (instructional) } \\
\text { skills }\end{array}$ & \multicolumn{2}{|c|}{$\begin{array}{c}\text { Control } \\
\text { group }\end{array}$} & $\begin{array}{c}\text { Experimental } \\
\text { group }\end{array}$ \\
\hline & Pre & Post & Pre & Post \\
\hline (1) Stating objectives & & & & \\
\hline M & 3.91 & 4.98 & 4.28 & 10.26 \\
\hline SD & 1.48 & 3.18 & 2.12 & 2.16 \\
\hline (2) Repeating points & & & & \\
\hline M & 5.46 & 6.28 & 5.90 & 12.80 \\
\hline SD & 1.38 & 3.86 & 1.38 & 2.56 \\
\hline (3) Using examples & & & & \\
\hline M & 3.83 & 8.91 & 5.96 & 11.90 \\
\hline SD & 1.75 & 2.52 & 1.12 & 2.26 \\
\hline (4) Repeating items & & & & \\
\hline M & 3.56 & 4.44 & 3.86 & 10.41 \\
\hline SD & 1.18 & 1.36 & 1.71 & 2.34 \\
\hline (5) Asking questions & & & & \\
\hline M & 4.95 & 8.75 & 5.98 & 11.90 \\
\hline SD & 2.23 & 2.22 & 1.66 & 1.44 \\
\hline (6) Student questions & & & & \\
\hline M & 4.37 & 4.90 & 4.90 & 9.86 \\
\hline SD & 1.46 & 2.24 & 1.30 & 3.22 \\
\hline (7) Practice time & & & & \\
\hline M & 5.36 & 11.76 & 4.89 & 12.90 \\
\hline SD & 2.21 & 2.22 & 1.25 & 1.76 \\
\hline Overall mean score & 4.89 & 7.93 & 5.70 & 11.79 \\
\hline & & & & \\
\hline
\end{tabular}

\section{- Research question two}

The teamwork developed in RTSM tried to be engaged with a reflective learning environment created by the respondents. "There seemed to be a good bond of unity in two (RTS members and teachers) arenas. They all helped each other. "According to teachers the reflective learning community created via the RTSM was much more different from the interactions that developed as a part of the triad. One of teachers said that he was "not observed by an outside person" in the RSTM.

The course lecturer was also happy to say that in terms of belonging or community, there was a great sense among the RTSM members than with triad model cooperating teachers. An academic staff said: "With the RTSM, I have had the chance to develop relationships with all the teachers. As I have the feeling of being a part of the meetings organized by the teams, I have established close relationships with the members of RTSM than I do as I am working with cooperating teachers".

As illustrated by the selection requirements for the RS model, RTSM members are school leaders and should have acted as cooperating teachers successfully, so the professional behaviors of them were observed by the teachers. In the responses given in survey, the teachers overwhelmingly 
indicated that they were "more professional" and had "higher expectations" than their cooperating teachers. One of the teachers noted this difference: "I believe that the supervision conducted by my RTSM member was very fruitful. She was very open in discussing problems" They were professional and supportive as well." On the open-ended question survey, majority of the teachers see med to recognize professionalism and professional leadership as a quality of their RTSM member as opposed to their cooperating teachers.

Put another way, RTS members interviewed acknowledged the sense of positive reinforcement, openness and professionalism through ownership, empowerment, and confidence that resulted from their participation in the RTS model. During one interview, when asked to explain in what ways the RTS model was different from the triad model, a RTS member explained that the model employed here made them an integral part of the teacher supervision process and that there was no need for and outside supervisor.

\subsection{Research question three}

Table 2 shows means and standard deviations for quality of use. Between group mean score comparisons at post-assessment showed statistical significance in favor of the experimental group for quality of use, $\mathrm{F}(1,32) \mathrm{D} 50.07, \mathrm{p}<.001$. Considering the open-ended questions, both groups indicated that overall professional growth had been accomplished and those who participated in RTSM made a lot of favorable comments.

The teachers overwhelmingly preferred the RTS model to the traditional triad. One of the reasons for this was that the RTS members interviewed felt more engaged and active for the supervision. According to them, their former engagement in the triad model had led them to feel isolated from the process of supervision. It seems to suggest that the recognition and responsibility enabled by the RTS model made them regard it as more efficient than the triad model.

The teachers showed that they chose the sustained and continuous o bservations of the RTSM to the formal and sporadic ones conducted by the supervisor. That was later supported by the fact that all teachers regarded the feedback and cross observations given by the other members of the RTSM as important as compared to the feedback given by the university supervisors. This result also correlates with the work of Follo (1999) who argues that the university supervisor did not have high effect on the student teachers. All teachers also regarded the RTS members as acting more professionally and having greater expectations than the cooperating teachers. According to these teachers, RTS model gave these them credibility as professionals.

Even though responses gained at during reflective conference sessions gave priority to instructional skills, the other considerations for the discussion on the task, teaching methods, materials and students were also available. The following examples of discourse reveal some of the anecdotal data.

\section{Example 1.}

Cooperating Teacher from the group Traditional Triad: What do you think of the weaknesses of the lesson?

Elementary School Teacher: At the beginning of the lesson, I happened to ask questions to create curiosity as part of brain storming. But it did not work. I could have used a video script form 
Göker, S. D. (2016). An alternative model of reflective teacher supervision. Journal of Human Sciences, 13(2), 35603570. doi:10.14687/jhs.v13i2.3868

a popular film about traffic rules or something reflecting examples, in which there could have been results of not obeying traffic rules.

\section{Example 2 .}

Cooperating Teacher from the group Traditional Triad: As the introduction part of the lesson was not interesting and your questions were not about their real life experiences, you lost the control. However, in the next teaching episode, we should take it into consideration.

Secondary School Teacher: That is right, I later realizes that they did not get excited and motivated.

\section{Example 3 .}

Cooperating Teacher from the group Traditional Triad: The insufficient numbers of examples affected your teaching method and you had to use direct method. Remember, I gave you some more IT devices they are using in their daily life.

Secondary School Teacher: You are right. During the previous reflective conference session, I remember we had discussed it in details.

To conclude, as can be seen in the Table 2, RTSM implemented in the study have contributed significantly to improving each instructional skill targeted.

\section{- Discussion and Implications}

Overall, the RTS model was regarded as preferable to the triad model and it was viewed more positively considering collegiality, quality of supervision, and communication than the triad model (Emans, 1983; Kagan \& Tippins, 1993).

Although pretest mean score differences for the two groups were not statistically significant for any of the variables, post-treatment results showed statistically significant differences in favor of the experimental group for all variables.

With regard to the open-ended surveys, both groups made statements to the fact that overall professional growth had been accomplished and those who participated in reflective teaching made a a lot of favorable comments about specific aspects of the field experience than those who did not participate. The area in which the fewest number of reflective teaching group teachers made positive responses related to ability to adapt to students' needs.

Findings in this study are also consistent with the extensive literature on reflective teaching, peer coaching with teachers (Bullock \& Hawk 2005, Costa \& Garmston, 2002; Goker 2006b; Tucker, Stronge, \& Gareis, 2002, Emans, 1983; Kagan \& Tippins, 1993) that found it was effective in a way that teachers reported a sense of freedom to ask questions and expressed their own opinions and increased demonstrations and efectiveness of instructional skills and self-confdence due to consistent feedback. All participants were also satisfed with the nature of the feedback they received received.

It is clearly seen that the results of this study are applicable to teacher education and supervision programs worldwide. On the whole, teacher educators should analyze ways to improve the role of the college supervisor. All teacher training programs should ensure that university supervisors have time in their schedules to discuss important issues and collaborate with the cooperating teacher 
Göker, S. D. (2016). An alternative model of reflective teacher supervision. Journal of Human Sciences, 13(2), 35603570. doi:10.14687/jhs.v13i2.3868

(Koehler, 1988) and do more than observe lessons on an infrequent basis as noted by the participants in this study.

Experiential activities, such as teaching practica or other mastery experiences, seem to have greater impact on teacher efficacy of pre-service teachers (Hoy and Woolfolk, 1990; Sia, 1992; Huffman \& Hipp, 2003). In university teacher education programs, the student teachers usually require more intensive supervisory efforts and are the critical test of the efficacy of supervision. Such experiences allow for a direct evaluation of one's abilities as a teacher Goker (2006b). Although one could rarely show that the two supervision models were equally robust, that would provide an argument in favor of RTSM to augment university supervision so that opportunities of observation, feedback, and guidance might be expanded.

RTSM is a part of reflective management and supervision practice and an important means for instituting collaborative efforts and improving teacher effectiveness when implemented both in preservice and in-service programs. It is also relatively not expensive and trained teachers in the field of reflective teaching and learning may be able to assist teachers as reflective supervisors or train new teacher supervisors over time.

Teacher training programs that prefer to use a model similar to the RTSM should take into consideration the impact that such a model had on the affective side of the teachers. In other words, the teachers indicated that they had received greater mentoring, the RTS members felt empowered, and they had developed a greater collegial relationship with all stakeholders. Such reflective learning communities lead a better understanding of the theories and philosophies of education because they can best be addressed in the realities of today's K-12 and university classrooms.

\section{References}

Acheson, K.A., \& Gall, M.D. (2003). Clinical supervision and teacher development: Preservice and inservice applications (5th ed.). New York, NY: John Wiley \& Sons, Inc.

Bullock, A. A., \& Hawk, P. P. (2005). Developing a teaching portfolio: A guide for preservice and practicing teachers. Upper Saddle River, NJ: Pearson Prentice Hall.

Costa, A., \& Garmston, R. (2002). Cognitive coaching: A foundation for renaissance schools. Norwood, MA: Christopher-Gordon.

Creswell, J. W. (2008). Educational research: Planning, conducting, and evaluating quantitative and qualitative research (3rd ed.). New Jersey: Pearson Education, Inc.

DuFour, R., DuFour, R., \& Eaker, R. (2009). Revisiting professional learning communites at work: New insights for improving schools. Bloomington, IN: Solution Tree.

Emans, R. (1983). Implementing the knowledge base: Rede- signing the function of cooperating teachers and college supervisors. Journal of Teacher Education, 34, 14-18.

Follo, E. (1999). The voices of student teachers (ERIC Document Reproduction Services No. ED 437 344).

Fullan, M. (2005). Leadership and sustainability: System thinkers in action (pp. 1-27). Thousand Oaks, CA: Corwin Press, Inc.

Göker, S. D. (2006a). Leading for learning: Reflective management in EFL. Theory into Practice. Spring 2006, Volume. 45, No. 2, pp. 187-196. 
Göker, S. D. (2016). An alternative model of reflective teacher supervision. Journal of Human Sciences, 13(2), 35603570. doi:10.14687/jhs.v13i2.3868

Göker, S. D. (2006b). Impact of peer coaching on self-efficacy and instructional skills in TEFL teacher education. System, An International Journal of Educational Technology and Applied Linguistics. 2006. 34/2 pp. 239-254.

Göker, S. D. (2012). Reflective leadership in EFL.Theory and Practice in Language Studies, 2(8): 1355.

Göker, S.D. (2015) .Denetim sürecinde ogretmen öğrenmesi için gelistirici bir geribildirim modeli. Asos Journal. The Journal of Academic Social Science, 3(10): 817-826.

Hoy, W. K. \& Woolfolk, A. E. (1990). Socialization of student teachers. American Educational Research Journal, 27, 279-300.

Huffman, J. B., \& Hipp, K. K. (2003). Reculturing schools as professional learning communities. Lanham, MD: Rowman \& Littlefield Publishing Group, Inc.

Kagan, D. M., \& Tippins, D. J. (1993). Benefits of crisis: The genesis of a school-university partnership. Action in Teacher Education, 15(4), 68-73.

Koehler, V. R. (1988). Barriers to effective supervision of student teaching: A field study. Journal of Teacher Education, 39(2), 28-34.

Kofman, F., \& Senge, P. (1993). Communities of commitment: The heart of the learning organization. Organizational Dynamics, 22(2), 5-23.

Krueger, R. (1994). Focus groups: A practical guide to applied research (2nd ed). Thousand Oaks, CA: Sage.

Metcalf, K. (1989). An investigation of the efficacy of a research-based regimen of skill development on the instructional clarity of pre-service teachers. Unpublished doctoral dissertation, The Ohio State University, Columbus. National StaV D.

Sergiovanni, T. J. (1996). Leadership for the schoolhouse. San Francisco: Jossey-Bass.

Shulman, Lee S. (1987). Knowledge and teaching: Foundation of the new reform. Harvard Educational Review 57, no. 1.

Sia, A.P. (1992). Preservice elementary teachers' perceived efficacy in teaching environmental education. Paper presented at the annual meeting of the North American Association for Environmental Education, Toronto, Ontario, Canada.

Tucker, P. D., Stronge, J. H., \& Gareis, C. R. (2002). Handbook on teacher portfolios for evaluation and professional development. Larchmont, NY: Eye on Education. 